NBER Working Paper No. 4355, May 1993

\title{
Currency Hedging Over Long Horizons *
}

\author{
Kenneth A. Froot \\ Harvard and NBER
}

April 20, 1993

\begin{abstract}
This paper reexamines the widely-held wisdom that the currency exposure of international investments should be entirely hedged. It finds that the previouslydocumented ability of hedges to reduce portfolio return variance holds at short horizons, but not at long horizons. At horizons of several years, complete hedging not only does not lower return variance, it actually increases the return variance of many portfolios. Hedge ratios chosen to minimize long-run return variance are not only low, they also have no perceptible impact on return variance. The paper reports and explores these results, their apparent causes, and investigates their implications for hedging practice.
\end{abstract}




\section{Currency Hedging Over Long Horizons}

\section{Introduction}

There is considerable disagreement about how international investors should think about currency risk. Should investors hold the currency components of their foreign investments, or should they hedge them out? What is the right currency hedge ratio in the absence of any special information? These questions are being posed repeatedly today, just as the international diversification question was posed a decade or two ago.

On the face of it, there is a simple and compelling argument in favor of hedging which has recently gained wide acceptance among practitioners. It says that investors should hedge fully because currency hedges do not lower expected returns, yet substantially reduce the risks of international investment. ${ }^{1}$ Empirical evidence (using high-frequency data) indeed suggests that exchange-rate changes in excess of the forward discount average about zero, and have virtually no correlation with almost any variable, including local-currency returns. It therefore appears as though the currency aspect of international investment is pure roulette - lots of independent risk which provides no additional average reward. International asset managers should therefore think of currency hedging as a foregone policy conclusion, or, in the words of Perold and Schulman (1988), as a "free lunch." 2

This paper reexamines the logic and evidence behind this popular argument. I argue that the "free-lunch" case for hedging is a short-horizon argument, and that it generally applies only if real exchange rates follow random walks. If, on the other hand, real exchange rates and asset prices display mean reversion, investors' optimal portfolio policies will generally depend on investor horizon. Investors with relatively long horizons may prefer to hedge a good deal less than the free-lunch

\footnotetext{
${ }^{1}$ Throughout the paper, the return on a currency hedge denotes the nominal return from holding short-term domestic bills less the domestic-currency cost of short-term, foreign-currency-denominated borrowing.

${ }^{2}$ While there are a number of papers that make this argument, the most influential have been those of Perold and Schulman (1988) and Black (1989). Their studies (as well as those by Madurs and Wollace (1985), Jorion (1989), Adler, Granito and Lee (1990), Burik and Ennis (1990), Kaplanis and Schaefer (1991), Nesbitt (1991), and Glen and Jorion (1992)) demonstrate that currency hedging can improve the risk-return tradeofl of a broad range of foreign portfolios using monthly and, in some cases, quarterly returns.
} 
argument would imply. ${ }^{3}$

I argue below that currency hedges have very different properties at long horizons compared with short horizons. The data show that while over short horizons hedging reduces risk substantially, over long horizons, hedging often does not reduce risk at all. In fact, at long horizons, many fully-hedged international investments actually have greater return variance than their unhedged counterparts.

The properties of currency hedges vary with horizon in part because hedge returns at different horizons are driven by very different factors. At relatively short horizons, hedge returns are dominated by changes in real exchange rates, i.e., in the purchasing power of one currency compared with another. However, mean reversion in real exchange rates implies that these purchasing powers tend toward parity, so that real exchange rates over time remain roughly constant. ${ }^{4}$ At long horizons, hedge returns are instead dominated by fluctuations in cross-country differences in unexpected inflation and real interest differentials. The importance of this latter component grows the longer the hedge remains in place. ${ }^{5}$

This decomposition of hedge returns into real exchange rate changes and inflation/real-interest-rate surprises is useful because most asset classes have very different exposures to the components. Unfortunately, common hedging instruments bundle the two components together, making it impossible to hedge each exposure separately. The result is that hedge ratios must strike a balance - for investors primarily concerned with long-horizon moments, hedge ratios should primarily reflect exposure to relative inflation and interest rate surprises, while for those concerned

\footnotetext{
${ }^{3}$ If investord can trade costlessly and continuously then horizons will not matter either if investor preferences are logarithmic, or if returns follow random walks and investor preferences are iso-elastic. (Samuelson (1960) and Merton (1969) show that investor horizon has no impact on asset allocation when returns tollow a ralution to their and Samuelson (1991), among others, showe that logarithmic invelors ane period to live) Section 6 below shows how multiperiod investment problem is the same as though they had only one period to live) Section broot (1993), which investor horieons generally matter in the presence of mean-reversiclicitly incorporated mean reversion and investor provides an equilibrium model of exchange-rate hedging that explicitly incorporated mean rever horizon.

See footnote 17 below for citations to the empirical literature on purchasing power parity.

${ }^{5}$ Mean reversion in real exchange rates generally implies that expected real returns (in domestic-ais allocations as international investments change over time. Investore may therefore wish to revise dhes pot imply that expected expected returne evolve. Note, however, that returns on currency hedges are time-varying.
} 
with short-horizon moments, hedge ratios should primarily reflect real-exchangerate exposure. In this sense, appropriate hedging policies can be quite sensitive to investment horizon.

To see this logic at work, consider the following example. Suppose that a US university endowment buys UK real estate. Suppose also that real-estate prices are linked to the local CPI, at least over the longer run. ${ }^{6}$ Furthermore, in order to avoid a "speculative" motive for hedging, assume that the expected return on hedge positions is zero. Should the endowment hedge the currency component of the real estate?

If there is a sudden fall in excess demand for the pound, both a nominal and real depreciation will result in the short run. To the extent that local real estate values are linked to the CPI, the real value of the UK real estate will also fall. In other words, real estate is highly exposed to real exchange rate changes. And, because real exchange-rate changes dominate hedge returns over short horizons, hedging can reduce the return variation of the real estate. Thus, the endowment should hedge if it wants to lower short-horizon return volatility.

This policy does not work, however, at long horizons. Over time, purchasing power parity (PPP) holds. Subsequent to the shock, the real value of the pound must rise, through some combination of higher-than-expected UK inflation or lowerthan-expected UK interest rates. Either way, the dollar value of the real estate will eventually be restored. In other words, at long horizons real estate is "naturally hedged $^{n}$ (for a given value of the real exchange rate) against inflation and interest rate surprises. Hedging thus does little to reduce long-horizon return volatility.

In fact, complete hedging may. actually add to long-horizon volatility. To see this, imagine that the endowment had hedged its investment in the financial markets. Years later, the value of the real estate would be the same as above, but the financial hedge would have yielded an additional profit from the pound's unexpected depreciation. If the opposite had occurred - that is, if the pound had appreciated

\footnotetext{
The assumption that real estate is linked to the CPI appears reasonable, both empirically and definitionally (CPIs are constructed using real estate prices). Howerer, as will become clear below, if this assumption is relaxced there is little reason to hedge even over short horizons.
} 
due to a similar disturbance in the US - the hedge position would show a loss. Thus, while the real estate is naturally hedged against inflation and interest rate surprises, these surprises dominate hedge returns at long horizons. In this way, the financial hedge can actually raise the volatility of real estate returns.

An identical set of arguments holds for UK stocks, which - as the results below suggest - appear to have exposures to real-exchange rate changes and past inflation/interest-rate surprises that are similar to those of real estate. That is, the real domestic value of foreign stocks is not very sensitive to such surprises, given the real exchange rate. ${ }^{7}$ On the other hand, the dollar value of UK stocks is highly sensitive to the real exchange rate. This exposure pattern implies that hedging can help reduce return variation at short horizons (where real-exchange rate changes dominate hedge returns), but not at long horizons (where relative inflation shocks dominate). Thus, a strategy of hedging international equity investments does not by itself reduce long-horizon return variance.

The critical implication of these examples is that a wide variety of international investments should probably not be hedged as aggressively when investors have long horizons. 8 The data presented below support this idea, and suggest that while complete hedging is the best strategy for investors who care primarily about short-horizon moments, no hedging at all is likely to be best for those who care primarily about long-horizon moments. The case for "going naked" becomes even stronger if one considers the transactions costs and counterparty risks that hedging inevitably adds. In practice, it may be that over long horizons, unhedged portfolios yield both lower long-horizon risk and higher average return than their fully-hedged counterparts.

In addition to shedding light on hedging policy, our analysis has implications for the appropriate benchmark against which the performance of foreign portfolios should be measured. For example, pension investors with a long investment horizon

\footnotetext{
${ }^{7}$ Boudoukh and Richardson (1993) show that while domestic stocks are approximately uncorrelated with domestic infiation over thort horizom, they are highly positively correlated with domestic inflation over long horizons.

"A similar argument holde for "nominal" aesets, such as foreign-currency-denominated bonds and bills. For detaile, see the discussion below.
} 
may wish to use an unhedged portfolio benchmark for evaluating their portfolio manager's performance. Investors with medium or short horizons, may prefer a partially or fully hedged benchmark. More generally, the formulation of hedge ratios should explicitly account for specific asset exposures and investment horizons.

The paper is organized as follows. Section 2 discusses measurement and data issues. Section 3 then examines the effect of currency hedges on return volatility of different asset classes at different horizons. Section 4 decomposes hedge returns into their two components - real interest differentials and changes in real exchange rates - and examines the properties of each. It also reports estimates of the asset exposures to the individual hedge components. In order to help understand what the long-horizon results imply for hedging practice, section 5 provides a theoretical examination of how optimal hedging demands are determined by investor horizon, preferences, and mean reversion in real exchange rates. Section 6 discusses several other implications of the results. Finally, section 7 concludes.

\section{Preliminaries}

\subsection{Notation and Methodology}

Consider a domestic investor with an investment, $X$, denominated in a foreign currency. Her k-period (log) real return can be written as:

$$
r_{t}^{k}=x_{t}^{k}+\Delta^{k} s_{t}-\pi_{d, t}^{k}
$$

where $x_{t}^{k}$ is the continuously-compounded return in local currency on the investment between time $t$ and $t+k ; \Delta^{k} s_{t}$ is the change in the log of the domestic-currency price of foreign exchange over the same time period; and $\pi_{d, t}^{k}$ is the change in the $\log$ of the domestic CPI.

An exchange-rate hedge involves short-term borrowing in one currency and lending in the other. Denote the $k$-period domestic-currency log return on such a hedge. by:

$$
h_{t}^{k}=\sum_{i=0}^{k-1} h_{t+i}^{1}, \quad h_{t}^{1}=\Delta^{1} s_{t}+i_{f, t}-i_{d, t},
$$


where $i_{f, t}$ is the continuously-compounded local-currency return on the foreign oneperiod riskless asset, and $i_{d, t}$ is the analogous return on the domestic riskless asset. Naturally, these hedge returns can be synthesized in the futures market or in the forward market by rolling over one-period contracts. ${ }^{9}$

Combining equations (1) and (2) yields the $k$-period return on a hedged investment:

$$
r_{t}^{k}-\phi h_{t}^{k}
$$

where $\phi$ is the hedge ratio. If $\phi>0$, the domestic investor is short the foreign currency, i.e., has borrowed in foreign currency and lent out the proceeds in domestic currency; if $\phi<0$ then the investor is short domestic currency. A value of $\phi=1$ corresponds to a complete beginning-of-period hedge of the foreign investment; i.e., borrowings of foreign exchange equal to the initial value of the investment $X$.

Hedging has an effect on average returns to the extent that the unconditional mean of $h_{t}^{1}$ is different from zero. There is a large literature examining the expectation of $h_{t}^{1}$, often referred to as the exchange risk premium. (For surveys see, for example, Froot and Thaler (1989) and Levich (1985).) The basic facts about this risk premium can be fairly summarized in two statements. First, empirical estimates of average risk premia are not significantly different from zero, either economically or statistically. ${ }^{10}$ (This is also true of the particular data sets used in this paper - see the results below.) There is thus no average foreign exchange premia that is comparable to the average premia on equities or bonds. ${ }^{11}$ Second, these empirical results are in agreement with most theoretical models of the exchange risk premium, which suggest that premia ought to be small. ${ }^{12}$

\footnotetext{
It is also possible to hedge a k-period investment with $k$-period borrowing and lending contracts (or with $k$-period forward contracts). However, in this paper we assume that the hedge employs only one-period instruments.

10 For atudies which discuss this result see, for example, Froot and Frankel (1989) and Rogoff (1979).

11 At quarterly or monthly frequencies, conditional expectations of $h^{1}$ (based on regreasion) have been found to be statistically different from zero. However, while these conditional expectations are quite large and variable, they oscillate between negative and positive, averaging about zero. It remains an unresolved question as to whether these high-frequency movements in conditional expectations are best interpreted as changea in risk (given investors' port folio holdings), or as opportunities for some traders to earn excess returns on marginal investments in foreign exchange. For a discussion of these issues in light of recent theory and atatistical modeling, see Froot and Thaler (1990).

12 For example, Frankel (1988) demonotrates that in mean-variance framework, foreign exchange premie will generally be limited to a few basis points for major currencies. Giovannini and Jorion (1988) reach similar conclusions.
} 
Taken together, these two facts suggest that we do little harm to the data or our priors if we assume that expected hedge returns equal their unconditional mean of zero (i.e., uncovered interest parity (UIP) holds). If UIP does not hold, so that conditionally expected hedge returns vary over time, use of the total return $h_{t}^{k}$ in (3) remains appropriate for investors who nevertheless wish to select a constant hedge ratio. ${ }^{13}$

To estimate the effects of hedging on the variance of real returns at different horizons, I first compute the $k$-period variance ratio of unhedged to fully hedged returns: ${ }^{14}$

$$
V^{k}=\frac{\operatorname{var}\left(r_{t}^{k}\right)}{\operatorname{var}\left(r_{t}^{k}-h_{t}^{k}\right)},
$$

A second, and related, approach is to estimate the minimum-variance hedge through a regression of the $k$-period unhedged return on the contemporaneous hedge return:

$$
r_{t}^{k}=\alpha^{k}+\beta^{k} h_{t}^{k}+\epsilon_{t}^{k}
$$

where $\beta^{k}$ is the minimum-variance hedge ratio.

The second approach allows for a straightforward test of the hypothesis that unhedged and fully hedged return variances are equal, i.e., that $V^{k}=1$. Under this hypothesis, $\operatorname{var}\left(r_{t}^{k}\right)=\operatorname{var}\left(r_{t}^{k}-h_{t}^{k}\right)$, which implies $\operatorname{var}\left(h_{t}^{k}\right)=2 \operatorname{cov}\left(r_{t}^{k}, h_{t}^{k}\right)$. If $\beta$ in (5) is given by the OLS estimator, $\beta=\frac{\operatorname{cov}\left(r_{t}^{k}, h_{t}^{k}\right)}{\operatorname{var}\left(h_{t}^{k}\right)}$, the hypothesis that $V^{k}=1$ can be written as $\beta=1 / 2$. Thus, a test of whether the minimum-variance hedge ratio equals $1 / 2$ is also a test of the hypothesis that unhedged and fully hedged return variances are equal. If $\beta>1 / 2$, the variance of hedged returns is smaller than that of unhedged returns, and if $\beta<1 / 2$ the reverse is true.

The $R^{2}$ s from the regressions can be interpreted as the amount of risk eliminated by the minimum-variance hedge. In a sense, this measure of hedging efficacy

\footnotetext{
${ }^{13}$ In order to see whether the results are sensitive to the assumption of UIP, I ran the tests below using several opecifications for time-varying expected hedge returns. The results were qualitatively unaffected.

14 The eatimates of $k$-period variances below include an adjustment for small sample bins under the hypothesis that the return processes are random walks with drift. Speciflcally, variances for all $k$ are taken around the same, one-period mean. An unbiased estimate of each component of (1) also requires a multiplicative degrees-of-freedom adjustment of $T / T-k+1$, where $T$ is the number of return observations during the sample period. See, for example, Cochrane (1988).
} 
is more important than the point estimate of $\beta$. If minimum-variance hedging has little effect on the variance of unhedged returns; then regardless of the magnitude of the minimum-variance hedge ratio, the case for hedging is weak.

\subsection{Data}

To learn about long horizon hedging, it is necessary to employ a long historical data sample. This paper uses data on US stock prices and US and UK interest rates from 1802 to 1990 obtained from Schwert (1990) and Siegel (1992). Since the longest and best-quality time series available are for US stocks and bonds, we focus on real returns on US instruments from the perspective of UK residents.

The stock index for the US is a total return index intended to resemble a broad group of individual stocks. ${ }^{15}$ The long-term-bond rate series is from Siegel (1992), ${ }^{16}$ as are the short-term interest rates. ${ }^{17}$

Exchange-rate data are from Diebold, Husted, and Rush (1991) and the original citations therein. The sample period spans a number of different exchange-rate regimes - gold standard, bimetalic standard, and floating currencies. During the early part of the sample the US was initially on a variety of metallic standards (1802 - 1862); it then left the gold standard and issued inconvertible paper currency, or greenbacks (1862-1879); the US then reinstated the gold standard and remained on it until 1913. Over this same period, the UK issued inconvertible paper (1802-1820),

\footnotetext{
${ }^{15}$ The index provides rather limited diversiflcation prior to 1870; until that time the index was comprised primarily of bank and railroad atocks.

${ }^{16}$ The series is a mixture of Treasury bond and high-grade municipal bond yields from 1802 to 1917 . After 1917, US government bonda are used. Holding period returna are calculated from the yield data using a linearized model of the term structure. This was done by computing McCaulay's (1936) measure of duration $(D)$, assuming that long-term yielda represented, on average, 15-year maturities, with coupons equal to the yield:
}

$$
D=\frac{1-\left(1+i_{c, b}\right)^{-T}}{1-\left(1+\left(1+i_{c, b}\right)^{-1}\right.}
$$

where $i_{t, b}$ represents the time-t yield on bonds, and $T=15$. (None of the results appear vensitive to the asaumption that $T=15$ years.) Next, the one-period holding return on bonds was calculated as:

$$
h_{t, b}^{1}=D i_{c, b}-(D-1)\left(i_{c+1, n}+\frac{T-1}{T}\left(i_{c+1, b}-i_{c+1, n}\right)\right)
$$

where $i_{1, n}$ is the time-t yield on one-period bills. Shiller, Campbell, and Schoenholtz (1983) show that this simple linearized model gives close approximations to various nonlinear models.

${ }^{17}$ Prior to 1920 , there was no short-term government or Treasury bill rate. Siegel therefore attempto to remove the risk premium from short-term US commercial paper rates during this period by using information from bond rates and the UK term premium. 
then remained on the gold standard for the rest of the period (1820-1913). Between 1913 and 1973, both the US and UK retained fixed exchange rates, except during brief periods when the exchange rate was allowed to float. During most of the 1973 - 1990 period, both currencies floated freely.

The main advantage of such a long sample period is that differences in the behavior of nominal and real exchange rates are easily detected. Studies which use shorter samples typically conclude that the real exchange rate is well-described by the same stochastic process that describes the nominal exchange rate - a random walk. ${ }^{18}$ This description of the real exchange rate may be approximately correct over short horizons. But over long horizons it is has a somewhat-implausible implication - i.e., that arbitrarily large deviations from purchasing power parity (PPP) among countries with similar income levels can be maintained indefinitely. A number of studies are able to reject this hypothesis, but they need to use longer time-series samples to gain power against the random-walk alternative. ${ }^{19}$

Of course, the use of this long time-series sample has disadvantages as well as advantages. One potential disadvantage is that prevailing monetary arrangements changed several times. During periods of fixed exchange rates, both nominal and real exchange rates tended to display considerably less short-horizon variability than they did during floating-rate periods. ${ }^{20}$

However, the long-horizon properties of the real exchange rate should be least affected by the nature of monetary arrangements - which, most economists believe, should have no long-run effects. Thus, the main bias created by the presence of fixed-rate periods in our sample is that hedging will appear relatively less important at short horizons than would be the case for a sample which consisted exclusively of floating rates. Note that this bias actually works toward strengthening our findings. That is, our results - which suggest that hedging is disproportionately less useful

\footnotetext{
1" Studiew which examine the random-walk behavior of real and nominal exchange rates include Roll (1979), Meese and Rogoff (1988), Mussa (1986), and Baille and McMahon (1989).

10 (10) for therein. Their dats put the half-life of real exchange-rate movements at between $\$$ and 5 years.

20 For more document ation of the effect of exchange-rate regime on short-horizon exchange-rate behavior, see Mussa (1986).
} 
at long horizons than at short horizons - would probably apply even more strongly if the present system of floating rates had been existence for almost 200 years.

\subsection{Summary statistics}

Tables 1 and 2 present summary statistics for the entire data set and two sub-samples. ${ }^{21}$ The tables help make several points. First, the pound/dollar real exchange rate has fluctuated considerably, but has not changed much on average over the last 180 years. ${ }^{22}$

Second, note that the real exchange rate is quite variable. Its standard deviation is about 9 percent per annum over the full sample, rising to 16 percent during the 1973-1991 floating-rate period. In addition, the real exchange rate exhibits strong (and statistically significant) negative autocorrelation at longer horizons, even though it is approximately uncorrelated at one-year horizons. (This pattern is suggestive of how hard it is to reject the random-walk hypothesis using highfrequency data.)

Third, the pound return on US stocks in Table 1 seems to inherit some of the real exchange rate's negative autocorrelation, particularly at longer horizons. (The negative autocorrelation of real dollar stock returns in Table 2 is much less pronounced at long horizons.) Table 1 also shows that this is not the case for bonds and bills.

\section{Hedged versus Unhedged Portfolios}

Table 3 compares the variance of unhedged and hedged real returns. Reported in the top panel is the variance ratio, $V^{k}$, for several US investments (from the perspective of UK residents) at short and long investment horizons. The middle and bottom panels display, respectively, the numerator and denominator of $V^{k}$, i.e., the variances of both unhedged and hedged returns (units are in percent per

\footnotetext{
21 There are many "natural" break points are in this data sample. The commencement of the recent floating rate period (1973) is useful to detect how different floating rates have been relative to the average experience. Because of the a number of problems with the atock index and the US price data prior to about 1880 , we also break the sample there. All of the tests below were run using these same breakpointe, with little evidence of parameter instability.

${ }^{22}$ Consumption in the US hed become more expensive relative to that in the UK (Table 1, line 1) at the rate of only 12 basis points per annum. Moreover, almoat all of this relative increase in US prices occurred in the 19th century, when the US was catching up to the UK in terms of economic development.
} 
annum). The investments are: US "real" assets whose nominal returns are given by changes in the US CPI (these assets might be thought of as a diversified portfolio of durables, including real estate); US stocks; US bonds; and US bills. The nominal returns on these asset classes are then converted into pounds and deflated by the change in the UK CPI.

Table 3 shows that the relative variance of unhedged returns declines as holding horizon increases. At one-year horizons, unhedged stock portfolios exhibit 13 percent more real-return variance than their hedged counterparts. However, when the horizon is increased to just three years, the variance of unhedged returns falls to a level marginally below that of hedged returns. Foreign bonds and bills also show a substantial decline in the relative variance of unhedged returns as the horizon increases.

Table 4 presents results from the estimation of equation (5). The top panel reports minimum-variance (MV) hedge ratios at various holding horizons. As expected from Table 3, the MV hedge ratios for all assets decline almost uniformly as the holding horizon increases. Hedge ratios for stocks decline more rapidly in the first few years than do those for other assets. In addition, the drop in point estimates is large from a policy perspective: while the short-horizon estimates suggest that variance is minimized through nearly complete hedging, the long-horizon estimates point toward MV hedge ratios of between 13 and 42 percent. ${ }^{23}$

At standard levels of statistical significance, it is possible to reject the hypothesis that the one-year MV hedge ratio equals one (which would imply that $\beta^{k}=1$ ) for real assets and bills, even though the point estimates are economically close to one. As one would expect, however, the standard errors increase markedly with the holding horizon. In spite of the long time-series sample, the data provide little power against the hypothesis that $\beta=1$ at very long investment horizons - we can reject this hypothesis at 7- or 8-year horizons only in the case of real assets.

\footnotetext{
2s As mentioned above, we might expect the short-horizon coefficient eotimates to be closer to one during aample periods which consist exclueively of floating exchange rates. Indeed, this seems to be the case; for example, using dats from the 1973-1991 sample only, the point estimates of $\beta_{j}^{1}$ are $0.87(0.06), 1.20(0.22), 0.74(0.21)$, and $0.96(0.08)$ for real assets, stocks, bonds, and bills, respectively (standard errors in parentheses).
} 
However, at more intermediate horizons of 3 and 4 years, there is enough power to reject $\beta^{k}=1$ for real assets, stocks, and bills. (For bonds it is possible to reject $\beta^{k}=1$ at the 10 percent level only at six-year horizons.)

The large standard errors make it even harder to reject the hypothesis that the variance of fully hedged and unhedged portfolios are equal, i.e., that $\beta_{j}^{k}=1 / 2$. For all of the asset classes at long horizons, the null hypothesis of $\beta_{j}^{k}=1 / 2$ cannot be rejected in favor of the alternative that $\beta_{j}^{k}<1 / 2$. However, it is possible to reject this null hypothesis at short horizons, albeit in favor of the alternative that $\beta_{j}^{k}>1 / 2$.

If hedging becomes less effective at longer horizons, we would expect not only that MV hedge ratios fall, but also that they reduce variance by less. This implies that the $R^{2}$ s from (5) ought to decline as holding horizon rises. Table 4 reports these $R^{2}$ in the middle panel. While hedging reduces return variation substantially at short horizons, the $R^{2}$ s fall dramatically at longer horizons. At horizons of 8 years, even the minimum-variance hedge has virtually no impact on real-return variation. Minimum-variance hedging remains most useful for real assets, where it leads to a 7 percent reduction in variance (versus a 42 percent reduction at one-year horizons). For stocks, bonds and bills, minimum-variance hedging has a reasonably large impact on short-horizon variance, but has essentially no ability to reduce long-horizon return variance.

To sum up, this section looked at two measures of currency hedging efficacy the magnitude of the MV hedge and the variance reduction the MV hedge affords. By both measures, currency hedging appears less effective at long horizons than at short. There is no evidence at relatively long horizons that currency hedging provides a reduction in return variation.

\section{Explaining differences between long- and short-horizon hedges}

This section explores the reasons behind the above results. The explanation posed in the introduction has two parts. It states that: i) real-exchange-rate changes dominate hedge returns over short horizons while relative inflation and interest-rate 
surprises dominate over long horizons; and $i i)$ asset exposures to real-exchange-rate changes are larger than exposures to relative inflation surprises (at least for "real" assets and stocks). In this section we look at both parts of this hypothesis.

\subsection{Decomposing hedge returns}

By adding and subtracting relative inflation on the right-hand side of (2), the hedge return can be rewritten as the change in the real exchange rate plus the cumulative short-term real interest differential:

$$
\begin{gathered}
h_{t}^{k}=\left(\Delta^{k} s_{t}+\pi_{f, t}^{k}-\pi_{d, t}^{k}\right)+\sum_{j=0}^{k-1}\left(\left(i_{f, t+j}-\pi_{f, t+j}^{1}\right)-\left(i_{d, t+j}-\pi_{d, t+j}^{1}\right)\right) \\
\equiv \Delta^{k} S_{t}+R_{t}^{k},
\end{gathered}
$$

where $\pi_{l, t}^{k}=\sum_{j=0}^{k-1} \pi_{l, t+j}^{1}, l=f, d$, is the $k$-period realized inflation in country $l$; $\Delta^{k} S_{t}$ is the $k$-period change in the log of the real exchange rate; and $R_{t}^{k}$ is the $k$-period ex post real interest differential.

If purchasing power parity holds in the long run, then real exchange rate changes are temporary, i.e., $S_{t}$ is mean-reverting. This implies that the per period variance of the real exchange rate will decline toward zero as horizon increases:

$$
\lim _{k \rightarrow \infty} \frac{\operatorname{Var}\left(\Delta^{k} S_{t}\right)}{k}=0
$$

Equation (8) will not generally hold for the other component of hedge returns, the $e x$ post real interest differential. To see this, note that the interest differential can be written as the sum of an $e x$ ante real interest rate plus a period-by-period relative inflation surprise,

$$
\begin{aligned}
& R_{t}^{k}=\sum_{j=0}^{k-1}\left(\left(i_{f, t+j}-\pi_{f, t+j}^{e}\right)-\left(i_{d, t+j}-\pi_{d, t+j}^{e}\right)\right) \\
& +\sum_{j=0}^{k-1}\left(\left(\pi_{d, t+j}^{1}-\pi_{d, t+j}^{e}\right)-\left(\pi_{f, t+j}^{1}-\pi_{f, t+j}^{e}\right)\right),
\end{aligned}
$$


where $\pi_{l, t+j}^{e}$ is the time-t+j expectation of inflation between time $t+j$ and $t+j+1$. Redefining the two terms on the right-hand side of.(9), we have:

$$
R_{t}^{k} \equiv D_{t}^{k}+\epsilon_{t}^{k}
$$

where $D_{t}^{k}$ is the sum of the ex ante real interest differentials between times $t$ and $t+k$, and $\epsilon_{t}^{k}$ is the sum of the one-step ahead errors made in predicting the actual inflation differential between times $t$ and $t+k$.

The second right-hand-side term in equations (9) and (10) is a random walk, so its average variance does not vanish as $k$ increases:

$$
\lim _{k \rightarrow \infty} \frac{\operatorname{Var}\left(\epsilon_{t}^{k}\right)}{k}=\sigma_{\epsilon}^{2},
$$

where $\sigma_{\epsilon}^{2}$ is the unconditional single-period variance of relative inflation surprises. In many models first term on the right-hand side of $(10), D_{t}^{k}$, also contains permanent components. $^{24}$ Either way, the variance of $R_{t}^{k}$ will have a component - that of relative inflation surprises - which grows linearly with $k .{ }^{25}$ The presence of these relative inflation surprises therefore suggests that the long-horizon variance of $h_{t}^{k}$ will be dominated by variation in $R_{t}^{k}$.

Is this characterization of hedge-return components borne out by the data? Table 5 examines the variances and cross-correlations of the hedge return and its components, $\Delta^{k} S_{t}$ and $R_{t}^{k}$. Note that the variance of $R_{t}^{k}$ does indeed grow more quickly with $k$ than that of $\Delta^{k} S_{t}$ : At ten-year horizons, the variance of $R_{t}^{k}$ increases to approximately 10 times the variance of $R_{t}^{1}$, while the corresponding variances of $\Delta^{k} S_{t}$ increase only about 5 fold. Furthermore, note that in Table 5 , the correlation between real-exchange-rate changes and hedge returns $\left(\rho_{1,2}\right)$ declines with increases in horizon, falling from 0.65 at 1 -year horizons to 0.21 at 10 -year horizons. Meanwhile, the correlation between real interest differentials and hedge returns $\left(\rho_{1,3}\right)$ increases from 0.27 to 0.41 .

\footnotetext{
24The simpleet description of the ex ante real intereat differential is probably the international Fisher hypotheais, which holds that $D^{k}=0$. In more complex monetary models, such as that of Dornbusch (1976), the time series of ex which holds that $D^{k}=0$. In more complex monetary models, such as that of Dornbusch (19terest differentiala is atationary (following a moving average procesa), so that $D^{k}$ (the $k$-period cumulative sum of ex arte real interest differentials) is nonstationary.

${ }^{25}$ This requires that the cumulative ex ante real intereat differential is not cointegrated with the cumulative relative inflation surprises with a cointegrating coefficient of negative one.
} 
Table 5 therefore provides some evidence in support of the first part of the hypothesis above - that as horizon increases, the real-exchange-rate component of hedge returns increases and the inflation/interest-rate-differential component decreases.

\subsection{Decomposing asset exposures}

The second necessary link for explaining the behavior of hedge ratios concerns the nature of asset exposures. Clearly, if most assets have the same degree of exposure to both components of the hedge return, then our decomposition is not very useful for understanding why MV hedge ratios change with horizon. However, based on the logic above, we would expect most assets to have different exposures to the hedge components. For example, it would seem natural for both "real" assets and stocks to be more sensitive to the real exchange rate than to relative inflation shocks (at a given real exchange rate).

To see this point, let us return to the endowment's purchase of UK real estate. If the dollar price of the real estate tracks the cost of living in the UK, the real dollar price will be influenced by the real exchange rate. However, because the real exchange rate is mean reverting, the long-run value of the real estate is essentially independent of current shocks to relative inflation and real interest rates. Thus, we expect to see greater exposure of real assets to the real exchange rate than to relative inflation or interest rate shocks. To the extent that equities behave like real assets, this long-horizon behavior ought to hold for stocks as well.

Fixed-income investments, on the other hand, are likely to be exposed to relative inflation shocks as well as to the real exchange rate. The magnitudes of these exposures will depend on the relative importance of domestic versus foreign inflation shocks.

To see this, suppose that the endowment buys a $k$-period zero-coupon UK bond. From (1), the $k$-period return on this foreign bond is $r_{b, t}^{k}=x_{b, t}^{k}+\Delta^{k} s_{t}-\pi_{d, t}^{k}$ and the change in the real exchange rate is $\Delta^{k} S_{t}=\Delta^{k} s_{t}+\pi_{f, t}^{k}-\pi_{d, t}^{k}$. For a given level of UK inflation $\left(\pi_{f, t}^{k}\right)$, the bond return moves one-for-one with shocks to the real 
exchange rate. This means that if there is a shock to US inflation, the real return on the foreign bond will be affected only to the extent that the real exchange rate changes. At long horizons the foreign bond is "naturally hedged" against domestic inflation shocks. Hedging will be helpful at short horizons, however, when changes in real exchange rates are large.

This situation is reversed if inflation shocks are primarily foreign. In that case, unexpected UK inflation depreciates the pound and causes a loss to the endowment even if the real exchange rate remains unchanged. In other words, the foreign bond's exposure to relative inflation shocks will be driven by the importance of foreign inflation shocks. When foreign inflation shocks dominate, hedging provides protection at short as well as at long horizons.

In sum, the component exposures of fixed-income investments will be determined by the source of inflation shocks. Larger foreign inflation shocks will increase the exposure to relative inflation surprises, and larger domestic inflation shocks will increase exposure to real exchange-rate changes.

\subsubsection{Measuring ass et exposures}

The next step is to measure these component exposures empirically. We therefore regress the foreign asset's real return on the two components of hedge returns - real interest differentials and real exchange rate changes:

$$
r_{t, l}^{k}=\alpha_{l}^{k}+\beta_{1, l}^{k} R_{t}^{k}+\beta_{2, l}^{k} \Delta^{k} S_{t}+\epsilon_{t, l}^{k}
$$

where $\beta_{1, l}^{k}$ and $\beta_{2, l}^{k}$ measure asset exposures to real interest differentials and realexchange-rate changes, respectively.

Note that the $\beta$ coefficients can be interpreted as hedge ratios if we think of $R_{t}^{k}$ and $\Delta^{k} S_{t}$ as returns on component hedge contracts. In fact, it is possible to interpret $\Delta^{k} S_{t}$ as the return on a "real" hedge contract, i.e., the return from borrowing and lending in each currency at "real bill" rates, which are indexed to actual inflation. ${ }^{26}$

\footnotetext{
${ }^{26}$ To make this interpretation work, it is necessary to assume that the Fisher hypothesis holds, and that the premium
} 
Under this interpretation, $\Delta^{k} S_{t}$ can be thought of as the return on a "real". hedge, and $R_{t}^{k}=h_{t}^{k}-\Delta^{k} S_{t}$ is the noise introduced by using nominal instead of "real" hedging contracts. While nominal and real magnitudes are often tightly linked at short horizons, their linkages are at best loose at long horizons. Thus, by looking at asset exposures to $\Delta^{k} S_{t}$ and $R_{t}^{k}$, we can determine whether our hypothetical "real" currency hedging contracts would provide better hedging vehicles than their nominal counterparts. ${ }^{27}$

\subsubsection{Estimation}

Table 6 displays estimates of equation (12). We report the $\beta$ coefficient estimates, their standard errors, and the regression $R^{2}$. As before, we can interpret the $\beta \mathrm{s}$ as MV hedge ratios and the $R^{2} \mathrm{~s}$ as the percentage reduction in return variances provided by the MV hedges. ${ }^{28}$

The results in Table 6 contrast strikingly with those in Table 4. First, note that exposures to real exchange rate changes are about full, i.e., $\beta_{2, l}^{k}=1$. These estimates are even slightly higher than the hedge ratios reported in Table 4. Furthermore, the exposure levels do not fall for stocks and bills as horizon increases. (Exposures do fall for bonds, albeit slightly.) The estimates of $\beta_{l}^{k}$ are generally statistically indistinguishable from 1, significantly greater than zero, and in many cases significantly greater than $1 / 2$. One interpretation is that complete hedging using real contracts would minimize variance regardless of horizon. Furthermore, portfolios hedged fully with our hypothetical real hedges exhibit significantly less return variance than do unhedged portfolios.

on short-term real bills over short-term nominally riskless bills is conatant. Using these two asoumptions, the retum on the one-period "real" hedge, $h_{r, l}^{1}$, equals the change in the real exchange rate (plus a conatant):

$$
h_{r, t}^{1}=\Delta^{1} s_{t}+c .
$$

\footnotetext{
${ }^{27}$ I also tried to estimate exposures to "real" hedge returns using specifications for expected inflation of other than the Fisher effect. For example, it might be reasonable to assume that expected next-period inflation is a linear function of current inflation,

$$
\pi_{l, t}^{e}=\alpha \pi_{l, t-1}^{1},
$$

where $\alpha$ is the first-order autocorrelation coefficient of actual infation. This assumption is realistic to the extent that actual infiation is closely approximated by an AR(1) process. The results reported below are not importantly effected by using this alternative specification.

${ }^{28}$ Under this apecification, the real return on US real assets is both the dependent variable and one of the regressors, i.e., $r_{t, l}^{k}=\Delta^{k} S_{t}$. As a consequence, no regults are reported in Table 6 for real assets.
} 
Second, note that the $R^{2}$ s do not decline with increases in horizon as substantially as they did in Table 4. Indeed, the $R^{2}$ for stock returns actually rises with $k$. This suggests not only that real exchange rate exposures remain large as horizon increases, but that hedging them would continue to result in substantial variance reduction.

Third, note that exposures to $R_{t}^{k}$ are positive at short horizons and become negative at longer horizons. The point estimates, however, are never statistically different from zero. The decline occurs most rapidly in stocks - at three-year horizons the estimate has already become negative - and much more slowly for bonds and bills. As we argued above, we would expect stocks to have relatively little relative-inflation-differential exposure to the extent that they behave like "real" assets. Bonds and bills, on the other hand, ought to have some real-interest-differential exposures, at least to the extent that the source of CPI shocks is domestic. The low estimates of $\beta_{1, l}^{k}$ for bonds and bills suggest that, in the sample, most CPI shocks originate in the UK.

Fourth, note that stocks do indeed behave like other "real" assets. That is, when the foreign currency depreciates, the price of foreign equities does not rise in the short run, even though it does rise in the long run. The fact that estimates of $\beta_{1, s}^{k}$ remain constant at about one suggests that the local currency value of stocks does ultimately rise, and that it does so at the same rate at which the real exchange rate returns to its long-run mean. In this sense, domestic stock prices behave like the relative domestic CPI - when consumption is relatively cheap in a country, its stocks are relatively cheap too.

Similar conclusions emerge from Table 7 . It reports the results from a regression of asset returns on the real exchange rate (or return on a "real" hedge contract) alone:

$$
r_{t, l}^{k}=\alpha_{l}^{k}+\beta_{2, l}^{k} \Delta^{k} S_{t}+\epsilon_{t, l}^{k}
$$

Once again, the estimates of $\beta_{2, l}^{k}$ remain near one as $k$ increases. This might be also be interpreted as showing that MV "real" hedge ratios are not affected by horizon. 
"Real" hedges also appear to substantially reduce return variance, even at long horizons. ${ }^{29}$

\section{Incorporating "long horizons" into investor asset demands}

While it would seem intuitively important for investors to consider both longand short-horizon moments of the data, standard finance theory provides relatively little guidance about impact of long-horizon moments on optimal asset allocation. This is partly because the results are sensitive to both the statistical properties of returns and investor preferences, and partly because the results are often complicated. The goal of this section is to provide a very simple example in which it is possible to see clearly the effects of mean reversion, investor horizon, and investor preferences on optimal hedging policy.

Consider, then, a 2-period model with a domestic investor who is concerned with the distribution of wealth at the end of date 2. Suppose that this investor can choose between foreign stocks and a domestic riskless asset, and that he allocates a fraction of wealth $-\omega_{1}$ at date 0 and $\omega_{2}$ at date $1-$ to foreign stocks. Assume also that these fractional allocations are continuously maintained between dates 0 and 1 , and dates 1 and 2 , respectively. During these periods, the local currency price of the foreign stock, $p(t)$, yields a geometric excess return (above the local riskless rate) of:

$$
d p(t)=\mu_{p, i} p(t) d t+\sigma_{p, i} p(t) d z_{p}, \quad i=1,2 \forall t \in[i-1, i] .
$$

We assume that the investor can hedge a fraction, $\phi$, of the foreign exchange exposure of the stocks by borrowing in foreign currency and lending in domestic currency. The excess return on the hedge evolves according to:

$$
d h(t)=\sigma_{h, i} h(t) d z_{h}, \quad i=1,2 \forall t \in[i-1, i]
$$

where we assume that the instantaneous correlation between the local-currency return on foreign stocks and the hedge return is given by $\rho$. Equation (15) implies

\footnotetext{
${ }^{20}$ Similar results emerge when using estimates of "real" hedge return! other than $\Delta^{k} S_{t}$. This suggests that the reaulto are not very sensitive to the particular assumptions needed to interpret $\Delta^{k} S_{1}$ as the retum on a "real" hedge.
} 
that hedge positions have zero expected returns from domestic investors' perspective. At time 0 , the investor also chooses a hedge ratio, $\phi$, which is continuously maintained until time 1. Also, assume for simplicity that the domestic interest rate is zero and that domestic consumption prices are fixed. The price of foreign consumption is fixed through date 1 , so that we can interpret $\frac{h(1)}{h(0)}$ as the change in the real exchange rate through date 1 .

In this setting, mean reversion in real asset prices can easily be added by making the expected future local-currency return on stocks, $\mu_{p_{1} 2}$, a declining function of the past real-exchange-rate change $\frac{h(1)}{h(0)}$. That is, subsequent to a current appreciation (depreciation) of the real exchange rate, the expected future local-currency return on stocks will be low (high). Specifically, we assume that $\mu_{p, 2}=\mu_{p, 1}-\alpha \frac{h(1)}{h(0)}$, where $\alpha=\frac{-\sigma_{h, p 2}}{\sigma_{h}^{2}}$; i.e., $\alpha=0$ implies that there is no correlation between current exchange-rate changes and future local-currency stock returns, and $\alpha=1$ implies that the entire increase in the current real exchange rate between dates 0 and 1 is on average offset through slower domestic-currency stock-price appreciation between dates 1 and 2.

Under these assumptions, the instantaneous return on the investor's wealth expressed in domestic currency, $R(t)$, can be written as:

$$
\frac{d R(t)}{R(t)}=\omega_{i}\left(\mu_{p, i}+\rho \sigma_{h, i} \sigma_{p, i}\right) d t+\omega_{i}\left(\sigma_{p, i}^{2}+(1-h)^{2} \sigma_{h, i}^{2}+2(1-h) \rho \sigma_{h, i} \sigma_{p, i}\right)^{\frac{1}{2}} d z
$$

which in turn yields an expression for the compounded full-period return on wealth from date 0 to 1 ,

$$
\begin{gathered}
R_{1} \equiv \frac{R(1)}{R(0)}=\left(\frac{p(1)}{p(0)}\right)^{\omega_{1}}\left(\frac{h(1)}{h(0)}\right)^{\omega_{1}(1-\phi)} \times \\
\exp \left(\omega_{1} \phi\left(\rho \sigma_{h, 1} \sigma_{p, 1}+(1-\phi) \frac{\sigma_{h, 1}^{2}}{2}\right)+\frac{\omega_{1}}{2}\left(1-\omega_{1}\right)\left(\sigma_{p, 1}^{2}+(1-\phi)^{2} \sigma_{h, 1}^{2}+2(1-\phi) \rho \sigma_{h, 1} \sigma_{p, 1}\right)\right),
\end{gathered}
$$

and a similar expression for the return on wealth from date 1 to 2 ,

$$
R_{2} \equiv \frac{R(2)}{R(1)}=\left(\frac{p(2)}{p(1)}\right)^{\omega_{2}}\left(\frac{h(2)}{h(1)}\right)^{\omega_{2}(1-\phi)} \exp \left(\frac{\omega_{2}}{2}\left(1-\omega_{2}\right) \sigma_{p, 2}^{2}\right)
$$


where we have assumed (without loss of generality) that there is no exchange-rate uncertainty between times 1 and 2, i.e., $\sigma_{h_{2} 2}=0$.

Next, let investor preferences be iso-elastic over time-2 wealth,

$$
E\left[U_{2}\right]=E\left[\left(R_{1} R_{2}\right)^{\gamma} /\right] / \gamma
$$

with $\gamma=0$ representing the case of logarithmic utility. The first-order condition with respect to the hedge ratio, $\phi$, is:

$$
E\left[\frac{\partial U_{2}}{\partial \phi}\right]=E\left[\left(R_{1} R_{2}\right)^{\gamma} \frac{\partial R_{1}}{\partial \phi R_{1}}\right]=0 .
$$

Straightforward computations and equations (14)-(19) allow us to solve (20) for the optimal hedge ratio, $\phi^{*}$, which is given by:

$$
\phi^{*}=1+\frac{\sigma_{h, p 1}}{\sigma_{h}^{2}}-\gamma\left(\frac{\operatorname{cov}\left[\ln \frac{h(1)}{h(0)}, \ln R_{2}\right]}{\sigma_{h}^{2} \omega_{1}^{*}}\right),
$$

where $\sigma_{h, p 1}=\rho \sigma_{h} \sigma_{p, 1}$ is the instantaneous covariance between local-currency stock returns and hedge returns between dates 0 and 1 .

Equation (21) shows how horizon and preferences enter into the determination of the optimal hedge ratio. A single-period investor will not care about $R_{2}$, and thus will regard the second term on the right-hand side of (21) as irrelevant. That is, a short-horizon investor will choose

$$
\phi^{* *} \equiv 1+\frac{\sigma_{h, p 1}}{\sigma_{h}^{2}} .
$$

Note that (22) is independent of the coefficient of relative risk aversion, $\gamma$. Add this to the fact that over short horizons $\sigma_{h, p 1} \approx 0$, and $\phi^{* *}$ represents the "free-lunch" result - i.e., that regardless of preferences, the optimal hedge ratio is near one.

As is well known, either of two conditions are sufficient to make the shorthorizon hedge ratio, $\phi^{* *}$, optimal for investors who have longer horizons. First, if investors have logarithmic utility $(\gamma=0)$, then they behave "myopically" regardless of their horizons. Second, if the investment opportunity set is constant (so that 
$\alpha=0$ ), then the covariance term in (21) is zero, and the short-horizon hedge ratio is optimal, even for non-log preferences.

In order to see how much long-horizon moments matter for non-log preferences, it is possible to rewrite (21) as:

$$
\phi^{*}=1+\frac{\sigma_{h, p 1}}{\sigma_{h}^{2}}+\gamma\left(\frac{\bar{\omega}_{2}^{*}}{\omega_{1}}\right)\left(\alpha+\alpha^{\prime} \frac{\gamma}{\gamma-1}\right),
$$

where $\omega_{1}$ is the fraction of wealth in stocks between dates 0 and $1,{ }^{30} \bar{\omega}_{2}^{*}$ is the median optimal fraction of wealth in stocks between dates 1 and $2,31 \alpha \equiv \frac{-\sigma_{h, p 2}}{\sigma_{h}^{2}}$ is a parameter indicating the degree of mean reversion in real stock prices, and $\alpha^{\prime}$ is a measure of how aggressively $\omega_{2}$ is expected to respond to the mean reversion in the real exchange rate $\left(\alpha^{\prime}=\alpha\right.$ indicates an optimal response to changing expected stock returns, whereas $\alpha^{\prime}=0$ indicates no response at all). That is, $\alpha^{\prime}$ measures how aggressively portfolio managers trade foreign equities on the basis of current deviations from PPP.

There are several points to note from (23). First, the hedge ratio declines as mean reversion is stronger (i.e., as $\alpha$ is greater) and as preferences are more risk averse (i.e., as $\gamma$ is more negative) ${ }^{32}$ Second, note that the investor hedges less when future holdings of foreign equities respond more aggressively to mean reversion in the real exchange rate (i.e., $\frac{d \phi}{d \alpha}<0$ ). Third, note that even if $\alpha^{\prime}=0$, mean reversion still tends to reduce the hedge ratio.

Finally, note that by increasing the amount of "time" between dates 1 and 2 , we can increase the effective "horizon" of the investor. When we do so, $\alpha$ (and

\footnotetext{
${ }^{30}$ The optimal fraction of wealth in stocks, $w_{i}$ ! follows from the other firat-order condition of equation (19), and is given by:$$
\omega_{i}^{*}=\frac{\mu_{p, 1}+\sigma_{h, p 1}}{\left(\sigma_{p, 1}^{2}+(1-\phi)^{2} \sigma_{h, 1}^{2}+2(1-\phi) \rho \sigma_{h, 1} \sigma_{p, 1}\right)(1-\gamma)}
$$

i.e., the instantaneous expected domestic-currency return on foreign stocks divided by the variance of domestic-

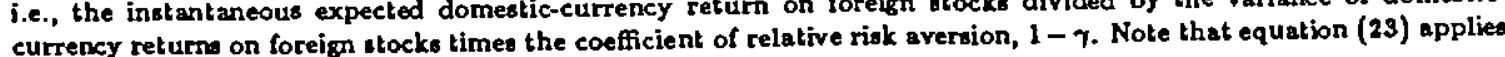
regardless of whether $\omega_{1}$ is set optimally.

${ }^{31}$ This is computed by taking the median of the date-2 optimal fraction of wealth in atocks:

$$
\omega_{2}^{*}=\frac{M\left[\mu_{p, 2}\right]}{\sigma_{p, 2}^{2}(1-\gamma)}=\frac{\mu_{p, 1}}{\sigma_{p, 2}^{2}(1-\gamma)},
$$

where $M$ implies the median operator, which is taken at date 0 with respect to the exchange-rate change between dates 0 and $1, h(1) / h(0)$. Note that, for plausible parametere, $\omega_{2}^{*} / \omega_{1}^{*}>1$.

${ }^{32}$ This result is even stronger than it might appear, as when $\phi$ decreases, so does the ratio $\frac{0_{7}^{*}}{w_{1}^{*}}$
} 
possibly $\alpha^{\prime}$ ) increase, as more of the return to PPP occurs on average by date 2. Thus, further increases in time horizon further lower the hedge ratio (given that preferences are more risk averse than $\log$, i.e., that $\gamma<0$ ).

It may be useful to calibrate this model. This will give us a sense for how sensitive optimal hedge ratios are to changes in preferences, horizon, and mean reversion. Suppose for a moment that $\gamma=-1$ (this is the "Samuelson presumption" that the coefficient of relative risk aversion equals 2). Also, think of date-1 as a "short" horizon (perhaps a year) and date-2 as a "long" horizon equal to the average half-life of a deviation from parity (about 3 to 5 years). This would imply $\frac{\sigma_{h, p l}}{\sigma_{h}^{2}} \approx 0$ and $\alpha \approx 0.5$. Finally, assume that $\alpha^{\prime}=\alpha$, so that portfolio managers respond optimally to any change in expected domestic-currency returns on foreign stocks. These assumptions imply that the optimal hedge ratio is considerably less than 0.25 ! Clearly, the optimal hedge ratio will be very sensitive to assumptions about risk aversion and length of horizon.

The optimal hedge ratio will also be sensitive to equilibrium returns on hedge contracts. In a one-period equilibrium model, Black (1989) shows that log-utility investors do not hedge at all (as compared with (23), which for plausible parameters, says they hedge completely). In Black's model, there is a greater temptation to bear foreign-exchange risk than in the model above because such foreign exchange exposure generates positive expected returns due to Siegal's paradox. Thus, investors in that model hedge fully only when they are considerably more risk averse than the log case. Froot (1993) provides an equilibrium model which allows for long-horizon mean-reversion of real exchange rates. In that model, optimal hedge ratios (for investors more risk averse than log) are lower than those implied by the Black model. This is because, in the presence of mean reversion, investors must bear considerably more risk if they wish to take advantage of the positive expected returns generated by Siegal's paradox. 


\section{Some additional implications}

\subsection{The timing of foreign investments}

The results above suggest that, in the short run, foreign stocks become cheaper in domestic terms when the foreign currency depreciates. However, over longer periods this effect disappears; these investments appear to "catch up" with the depreciation of the local currency. Thus, subsequent to a depreciation of the local currency, expected returns on foreign stock appear relatively high. Note that - as in the model of the previous section - the increase in expected returns need not come from an opportunity to buy the currency cheap. That is, uncovered interest parity can still hold. ${ }^{33}$

One might worry that this feature of stock returns is an artifact of such a long historical sample. In the rapidly-integrating international capital market of today, perhaps this effect has disappeared. However, to this day, high frequency correlations between local-currency stock returns and the domestic exchange rate remain about zero. If, in the long run, PPP still holds - and greater international integration suggests that, if anything, it does so more strongly today - then this characterization of changing expected returns still persists. Furthermore, if we reach a day in which high-frequency currency fluctuations and local-currency returns become more highly correlated, then even the "free-lunch" case for hedging will disappear. That is, if there is little exchange-rate exposure (even over the short run) in foreign assets in the first place, then there is clearly less impetus to hedge.

\subsection{Corporate risk management}

Corporations which make physical investments abroad often borrow in local currency. "Currency hedging" is frequently given as the rationale for such localcurrency borrowing, although there are other good explanations for it (e.g., hedging the risks of expropriation).

What are the implications of the above results for such financing decisions? . To

\footnotetext{
${ }^{\text {ss }}$ This paper has not attempted to sort out how much of the increase in expected returns is attributable to currencies versue the assets themselves. I leave that for future work.
} 
see this, consider a multinational corporation which wishes to borrow to finance a long-term investment abroad. Suppose that the expected cost of local- and homecurrency debt are the same, and that the company wishes to choose a debt structure that minimizes return volatility of the entire foreign operation. ${ }^{34}$ What fraction of the borrowing should be in local currency?

If purchasing power parity holds, then over time the physical assets are likely to be naturally hedged. And, if the assets have little long-horizon currency exposure, the currency composition of debt does not help to hedge the physical assets. To the extant that this is true, the problem of hedging the returns on the entire foreign operation comes down to that of hedging the fluctuations in real borrowing costs.

At this point, the logic from above can be applied directly. If the foreign country is known for its unpredictable and highly volatile inflation rate, then over long periods, it is likely that local-currency debt will have relatively high realreturn volatility. If, on the other hand, it is the home-currency's inflation rate that is volatile and unpredictable, then the home-currency debt will have relatively high real-return volatility. The fraction of borrowing in local currency should therefore be an increasing function of the volatility of real borrowing costs in the home country relative to that in the local country. In general, the mix ought to be part of the corporation's overall risk management strategy.

\section{Conclusions}

This paper has argued that currency hedges are less useful at reducing realreturn variance at long horizons than they are at short horizons. In a data set of US financial returns over 200 years we showed that this intuition is borne out over the sample from the perspective of British international investors.

The data show that at short horizons, full hedging reduces return volatility.

\footnotetext{
${ }^{34}$ According to Modigliani-Miller, firms cannot create value by changing the structure of their liabilities, and therefore should not be concerned with the return volatility implied by a particular debt atructure. However, there are a number of reasons why firmo may wish to hedge out return volatility. Froot, Scharfotein and Stein (1993) review several motivations for corporate hedging policies and develop a theory of corporate hedging based on costly external flnance.

This example contrast local-and home-currency debt. However, it should be clear that the logic is easily extended to include debt denominated in third currencieg.
} 
However, for horizons of five years or more, foreign stocks display greater return volatility when hedged than when unhedged. For foreign bonds the cross-over point is about eight years. I also report minimum-variance hedge ratios at different horizons. This ratio falls from almost 100 percent hedged at short horizons to an average of about 35 percent at horizons of 5 to 10 years. Moreover, at these longer horizons, even the minimum-variance hedge cannot reduce return volatility below that of the unhedged portfolio. Thus, if hedging involves even small transactions costs and counterparty risks, the optimal hedge ratio will decline rapidly toward zero as the investment horizon increases.

There are several caveats to these results. First, this paper has focused primarily on how hedging effects the variance of an individual asset class. However, hedge ratios - like other asset allocation decisions - should always be determined according to their effects on the entire portfolio. ${ }^{35}$

A second caveat concerns the applicability of the long-horizon moments which are discussed and measured above. A single long-horizon data base is surely better than none at all, but alone it is insufficient. It would clearly be helpful to have additional long-horizon data from other country experiences.

\footnotetext{
ss Other work has demonstrated that over short horizons, currency hedging can reduce the volatility of widely diveraifed portfolios which contain domestic as well as foreign components. See, for example, Glen and Jorion (1992).
} 


\section{References}

Adler, Michael, M. Granito, and A. Lee, "Should International Portfolios Be Permanently Hedged?" in The Currency Hedging Debate, L. Thomas, ed., London: IFR Publishing.

Baillie, Richard T., and McMahon, Patric C., The Foreign Exchange Market: Theory and Econometric Evidence. Cambridge: Cambridge University Press, 1989.

Black, Fischer, "Universal Hedging: How to Optimize Currency Risk and Reward in International Equity Portfolios," Financial Analysts Journal, July/August 1989, Vol. 45, No. 4, 16-22.

Boudoukh, Jacob, and Matthew Richardson, "Stocks Are a Good Hedge for Inflation (In the Long Run)," University of Pennsylvania, Wharton School, forthcoming American Economic Review, 1993.

Burik, Paul and Ennis, Richard, "Foreign Bonds in Diversified Portfolios: A Limited Advantage," Financial Analysts Journal, March/April 1990, 46-2, 31-44.

Cochrane, John, "How Big is the Random Walk in GNP?," Journal of Political Economy,96 (October 1988), 893-920.

Diebold, Francis, Steven Husted, and Mark Rush, "Real Exchange Rates under the Gold Standard," Journal of Political Economy, 99 (December 1991), 1252-71.

Dornbusch, Rudiger, "Expectations and Exchange Rate Dynamics," Journal of Political Economy, 84 (December 1976), 1161-76.

Frankel, Jeffrey A., "International Capital Mobility and Crowding out in the US Economy: Imperfect integration of Financial Markets or of Goods Markets?," in How Open is the US Economy?ed. by R.W. Hafer, Lexington, Mass: Lexington, 1986.

Frankel, Jeffrey A. "Recent Estimates of Time Variation in the Conditional Variance and in the Exchange Risk Premium," Journal of International Money and Finance, 7 (March 1988).

Froot, Kenneth A., "Another Universal Hedge Ratio," (in progress) Harvard University, 1993. 
Froot, Kenneth A. and Jeffrey A. Frankel, "Forward Discount Bias: Is It an Exchange Risk Premium?," Quarterly Journal of Economics, 416 (February 1989), 139-161.

Froot, Kenneth A., David S. Scharfstein, and Jeremy Stein, "Risk Management: Coordinating Corporate Investing and Financing Policies, ${ }^{n}$ Harvard University, February 1993.

Froot, Kenneth A., and Richard Thaler, "Anomalies: Foreign Exchange," Journal of Economic Perspectives, 4 (Summer 1990), 179-192.

Giovannini, Alberto, and Philippe Jorion, "Foreign-Exchange Risk Premia Volaility Once Again, ${ }^{n}$ Journal of International Money and Finance, 7 (March 1988).

Glen, Jack, and Philippe Jorion, "Currency Hedging for International Portfolios," Columbia University, 1992.

Huizinga, John, "An Empirical Investigation of the Long-Run Behavior of Real Exchange Rates," in Empirical Studies of Velocity, Real Exchange Rates, Unemployment, and Productivity, ed. by Karl Brunner and Allan H. Meltzer, Carnegie-Rochester Conference Series on Public Policy, vol. 27, Amsterdam: North-Holland, 1987.

Jorion, Philippe, "Asset Allocation with Hedged and Unhedged Foreign Assets, "Journal of Portfolio Management, 15 (1989), 49-54.

Kaplanis, E., and S Schaefer, "Exchange Risk and International Diversification in Bond and Equity Portfolios," Journal of Economics and Business, 43 (1991) 287-308.

Levich, Richard, "Empirical Studies of Exchange Rates: Price Behavior, Rate Determination and Market Efficiency," in W.R. Jones and P.B. Kenen, eds., Handbook of International Economics, Volume 2. Amsterdam: North Holland, 1985.

Madura, J., and R. Wallace, "A Hedge Strategy for International Portfolios," Journal of Portfolio Management, 12 (1985), 70-74.

Macaulay, F.R., Some Theoretical Problems Suggested by Movements of Interest Rates, Bond Yields and Stock Prices in the United States Since 1856, New York, NBER, 1938. 
Merton, Robert C., “An Intertemporal Capital Asset Pricing Model," Econometrica, 41 (September 1973), 867-87.

Merton, Robert C., "Lifetime Portfolio Selection Under Uncertainty: The Continuous-Time Case," Review of Economics and Statistics, 51 (August 1969), 247-57.

Meese, Richard, and Kenneth Rogoff, "Was it Real? The Exchange RateInterest Differential Relation over the Modern Floating-Rate Period," Journal of Finance, 43 (September 1988), 933-48.

Mussa, Michael, "Nominal Exchange Rate Regimes and the Behavior of Real Exchange Rates: Evidence and Implications," in Real Business Cycles, Real Exchange Rates and Actual Policies, K. Brunner and A.H. Meltzer, eds., Carnegie-Rochester Conference Series on Public Policy, 25. Amsterdam: North Holland, 1986.

Nesbitt, Stephen, "Currency Hedging Rules for Plan Sponsors," Financial Analysts Journal, March/April 1992, 47-2, 73-81.

Perold, André, and Evan Schulman, "The Free Lunch in Currency Hedging: Implications for Investment Policy and Performance Standards, ${ }^{n}$ Financial Analysts Journal, May/June 1988, 45-50.

Roll, Richard, "Violations of Purchasing Power Parity and their Implications for Efficient International Commodity Markets," in International Finance and Trade, volume 1, M. Sarnat and G.P. Szegö. Cambridge, Mass.: Ballinger, 1979.

Rogoff, Kenneth, "Essays on Expectations and Exchange Rate Volatility," Ph.D. Dissertation, Massachusetts Institute of Technology, 1979.

Samuelson, Paul, "Lifetime Portfolio Selection by Dynamic Stochastic Programming," Review of Economics and Statistics, 51 (August 1969), 239 46.

Schwert, William, "Indexes of Stock Prices from 1802 to 1987," Journal of Business, 63 (1990), 399-426.

Shiller, R.J., J.Y. Campbell and K.L. Schoenholtz, "Forward Rates and Future Policy: Interpreting the Term Structure of Interest Rates," Brookings Papers on Economic Activity, 1873, 223-242.

Siegel, Jeremy, "The Real Rate of Interest from 1800-1990: A Study of the US 
and UK, " Journal of Monetary Economics, 1992. 
Table 1

Summary Statistics:

Cross-Currency Returns at Different Investment Horizons

1802-1991

1880-1972

1973-1991

\begin{tabular}{|c|c|c|c|c|c|c|c|c|c|c|}
\hline Return on: & Variable & mean & s.d. & $\rho_{1}$ & mean & s.d. & $\rho_{1}$ & mean & s.d. & $\rho_{1}$ \\
\hline foreign stocks & $r_{t, 1}^{1}$ & 6.02 & 19.60 & 0.05 & 6.46 & 21.81 & 0.09 & 3.08 & 24.16 & 0.24 \\
\hline \multirow[t]{3}{*}{ (real domestic return) } & $r_{t, d}^{3}$ & 18.25 & 31.99 & 0.19 & 19.50 & 33.99 & 0.25 & 10.49 & 31.05 & 0.02 \\
\hline & $r_{t, 2}^{5}$ & 30.28 & 42.71 & 0.25 & 32.49 & 40.95 & 0.15 & 17.49 & 44.77 & 0.39 \\
\hline & $r_{t, 0}^{10}$ & 60.27 & 44.93 & 0.40 & 64.99 & 69.01 & 0.60 & NA & NA & NA \\
\hline foreign bonds & $r_{t, b}^{1}$ & 3.34 & 10.65 & 0.19 & 2.55 & 11.37 & 0.18 & 0.48 & 17.26 & 0.18 \\
\hline \multirow[t]{3}{*}{ (real domestic return) } & $r_{t, b}^{3}$ & 10.12 & 19.42 & 0.12 & 7.55 & 21.01 & 0.03 & 1.69 & 32.80 & 0.21 \\
\hline & $r_{t, b}^{5}$ & 16.97 & 28.50 & 0.07 & 12.58 & 28.81 & 0.17 & 2.82 & 27.03 & 0.19 \\
\hline & $r_{t, b}^{10}$ & 31.89 & 45.18 & 0.10 & 25.16 & 53.68 & 0.16 & NA & NA & NA \\
\hline foreign bills & $r_{t, n}^{1}$ & 2.91 & 10.46 & 0.24 & 1.46 & 11.03 & 0.25 & 0.95 & 16.41 & 0.13 \\
\hline \multirow[t]{3}{*}{ (real domestic return) } & $r_{t, n}^{3}$ & 8.96 & 19.17 & 0.06 & 4.58 & 20.57 & 0.01 & 1.54 & 30.65 & 0.28 \\
\hline & $r_{t, n}^{5}$ & 14.91 & 27.90 & 0.03 & 7.63 & 25.66 & 0.18 & 2.57 & 31.94 & 0.64 \\
\hline & $r_{t, n}^{10}$ & 30.44 & 43.87 & 0.15 & 15.25 & 46.83 & 0.34 & NA & NA & NA \\
\hline Currency hedge & $h_{t}^{1}$ & 0.55 & 7.54 & 0.01 & 0.56 & 8.03 & 0.03 & 1.91 & 16.29 & 0.10 \\
\hline \multirow[t]{3}{*}{ (nominal domestic return) } & $h_{t}^{3}$ & 1.95 & 10.36 & 0.36 & 1.65 & 9.23 & 0.10 & 2.99 & 30.56 & 0.64 \\
\hline & $h_{t}^{5}$ & 3.25 & 12.41 & 0.53 & 2.75 & 14.13 & 0.22 & 4.99 & 27.84 & 1.74 \\
\hline & $h_{t}^{10}$ & 7.83 & 13.17 & 0.51 & 5.51 & 20.20 & 0.42 & NA & NA & NA \\
\hline \multirow[t]{4}{*}{ Real exchange rate } & $r_{t, .}^{1}$ & 0.12 & 8.74 & 0.04 & 0.29 & 8.62 & 0.01 & 2.47 & 14.61 & 0.04 \\
\hline & $r_{t, e}^{3}$ & 0.56 & 13.99 & 0.18 & 1.13 & 12.79 & 0.14 & 5.93 & 22.82 & 0.52 \\
\hline & $r_{t, e}^{5}$ & 0.86 & 19.55 & 0.38 & 1.89 & 13.84 & 0.07 & 9.89 & 26.85 & 1.11 \\
\hline & $r_{t, e}^{10}$ & 2.91 & 20.50 & 0.52 & 3.78 & 23.00 & 0.77 & NA & NA & NA \\
\hline
\end{tabular}

Notes to Table 1: Variables are defined as follows: $h_{t}^{k} \equiv \sum_{j=0}^{k-1}\left(i_{f, t+j}-i_{d, t+j}\right)+\Delta^{k} s_{t}$, where $i_{l, t} l=d, f$ denotes the continuously compounded one-period interest rate at time $t$ in the domestic and foreign currencies, respectively, and $\Delta^{k} s_{t}$ is the log of the $k$-period change in the domestic price of foreign currency from time $t$ to $t+k ; r_{t, \mathbb{Q}}^{j} \equiv \sum_{j=0}^{k-1} x_{t+j, 0}^{1}-\pi_{t+j, d}^{1}+\Delta^{1} s_{t+j}$, where $x_{t, \text { }}^{1}$ denotes the continuously compounded one-period return on an portfolio of U.S. stocks, and $\pi_{t, d}^{1}$ is the continuously compounded one-period change in the log of the U.K. CPI; $r_{t, b}^{i} \equiv$ $\sum_{j=0}^{k-1} x_{t+j, b}^{1}-\pi_{d, t+j}^{1}+\Delta^{1} s_{t+j}$, where $x_{t, b}^{1}$ denotes the continuously compounded one-period return on U.S. government (and sometimes commercial) bonds; $r_{t, n}^{j} \equiv \sum_{j=0}^{k-1} x_{t+j, n}^{1}-\pi_{d, t+j}^{1}+\Delta^{1} s_{t+j}$, where $x_{t, n}^{1}$ denotes the continuously compounded one-period return on U.S. government (and some- 
times commercial) short-term bills; and $r_{t, c}^{j} \equiv \sum_{j=0}^{k-1} \pi_{f, t+j}^{1}-\pi_{d, t+j}^{1}+\Delta^{1} s_{t+j}$ is the continuously compounded one-period change in the log of the real exchange rate. 


\section{Table 2}

\section{Summary Statistics:}

U.S. Real Returns at Different Investment Horizons

1802-1991

$1880-1972$

1973-1991

\begin{tabular}{|c|c|c|c|c|c|c|c|c|c|c|}
\hline Return on: & Variable & mean & s.d. & $\rho_{1}$ & mean & s.d. & $\rho_{1}$ & mean & s.d. & $\rho_{1}$ \\
\hline foreign stocks & $y_{i, 0}^{1}$ & 5.90 & 17.32 & 0.01 & 6.17 & 19.00 & 0.02 & 5.55 & 15.66 & 0.32 \\
\hline \multirow[t]{3}{*}{ (real foreign return) } & $y_{t, 0}^{3}$ & 17.69 & 30.70 & 0.30 & 18.36 & 32.09 & 0.30 & 16.43 & 16.68 & 0.46 \\
\hline & $y_{i, 0}^{5}$ & 29.42 & 37.57 & 0.42 & 30.60 & 35.91 & 0.29 & 27.38 & 30.87 & 0.32 \\
\hline & $y_{t, 0}^{10}$ & 57.37 & 38.22 & 0.07 & 61.21 & 53.14 & 0.48 & $\mathrm{NA}$ & NA & NA \\
\hline foreign bonds & $y_{\ell, b}^{1}$ & 3.22 & 7.48 & 0.43 & 2.26 & 6.06 & 0.53 & 1.99 & 12.30 & 0.33 \\
\hline \multirow[t]{3}{*}{ (real foreign return) } & $y_{t, b}^{3}$ & 9.56 & 17.69 & 0.16 & 6.42 & 14.81 & 0.16 & 4.24 & 29.19 & 0.40 \\
\hline & $y_{t, b}^{5}$ & 16.11 & 23.11 & 0.15 & 10.69 & 24.14 & 0.11 & 7.07 & 32.38 & 0.19 \\
\hline & $y_{t, b}^{10}$ & 28.98 & 35.99 & 0.36 & 21.38 & 42.24 & 0.02 & NA & $\mathrm{NA}$ & NA \\
\hline foreign bills & $y_{i, n}^{1}$ & 2.79 & 6.16 & 0.53 & 1.17 & 5.07 & 0.66 & 1.51 & 4.20 & 0.61 \\
\hline \multirow[t]{3}{*}{ (real foreign return) } & $y_{i, n}^{3}$ & 8.41 & 15.09 & 0.21 & 3.44 & 13.12 & 0.21 & 4.39 & 11.04 & 0.34 \\
\hline & $y_{i, n}^{5}$ & 14.06 & 18.34 & 0.43 & 5.74 & 19.87 & 0.21 & NA & 14.07 & 0.43 \\
\hline & $y_{t, n}^{10}$ & 27.54 & 32.07 & 0.43 & 11.48 & 34.83 & 0.08 & 2.74 & NA & NA \\
\hline
\end{tabular}

Notes to Table 2: Variables are defined as follows: $y_{t, 0}^{j} \equiv \sum_{j=0}^{k-1} x_{t+j, 0}^{1}-\pi_{f, t+j}^{1}$, where $x_{\ell, 0}^{1}$, denotes the continuously compounded one-period return on an portfolio of U.S. stocks, and $\pi_{f, t}^{1}$ is the continuously compounded one-period change in the log of the U.S. CPI; $y_{t, b}^{j} \equiv \sum_{j=0}^{k-1} x_{t+j, b}^{1}-$ $\pi_{f, t+j}^{1}$, where $x_{i, b}^{1}$ denotes the continuously compounded one-period return on U.S. government (and sometimes commercial) bonds; and $y_{t, n}^{j} \equiv \sum_{j=0}^{k-1} x_{t+j, n}^{1}-\pi_{f, t+j}^{1}$, where $x_{t, n}^{1}$ denotes the continuously compounded one-period return on U.S. government (and sometimes commercial) short-term bills. 
Table 3

Real Returns on Foreign Investments:

Unhedged versus Fully Hedged

Horizon ( $k$ years)

$\begin{array}{lllllllllll}\text { Variable } & 1 & 2 & 3 & 4 & 5 & 6 & 7 & 8\end{array}$

\begin{tabular}{|c|c|c|c|c|c|c|c|c|c|}
\hline \multirow[b]{2}{*}{ foreign real assets. } & \multirow[b]{2}{*}{$V_{t ; c}^{k}$} & \multicolumn{8}{|c|}{ Variance Ratios } \\
\hline & & 1.71 & 1.43 & 1.33 & 1.23 & 1.07 & 0.95 & 0.86 & 0.82 \\
\hline foreign stocks & $V_{t, d}^{k}$ & 1.13 & 1.03 & 0.99 & 0.97 & 0.95 & 0.96 & 0.97 & 0.98 \\
\hline foreign bonds & $V_{t, b}^{k}$ & 1.55 & 1.39 & 1.32 & 1.25 & 1.12 & 1.04 & 0.99 & 0.98 \\
\hline \multirow[t]{2}{*}{ for eign bills } & $V_{t, n}^{k}$ & 1.38 & 1.27 & 1.21 & 1.13 & 1.02 & 0.97 & 0.96 & 0.96 \\
\hline & & \multicolumn{8}{|c|}{ Variance of Unhedged Returns (\% per annum) } \\
\hline foreign real assets & $\operatorname{Var}\left(r_{t, c}^{k}\right)$ & 0.80 & 0.83 & 0.79 & 0.75 & 0.67 & 0.62 & 0.55 & 0.52 \\
\hline foreign stocks & $\operatorname{Var}\left(r_{t, 0}^{k}\right)$ & 3.79 & 3.63 & 3.23 & 3.26 & 3.15 & 3.01 & 3.01 & 3.02 \\
\hline foreign bonds & $\operatorname{Var}\left(r_{t, b}^{k}\right)$ & 1.12 & 1.38 & 1.49 & 1.56 & 1.54 & 1.53 & 1.54 & 1.59 \\
\hline \multirow[t]{2}{*}{ foreign bills } & $\operatorname{Var}\left(r_{t, n}^{k}\right)$ & 1.22 & 1.49 & 1.59 & 1.65 & 1.62 & 1.64 & 1.69 & 1.76 \\
\hline & & \multicolumn{8}{|c|}{ Variance of Hedged Returns (\% per annum) } \\
\hline foreign real assets & $\operatorname{Var}\left(r_{t, c}^{k}-h_{t}^{k}\right)$ & 0.47 & 0.58 & 0.59 & 0.61 & 0.63 & 0.65 & 0.64 & 0.63 \\
\hline foreign stocks & $\operatorname{Var}\left(r_{t, 0}^{k}-h_{t}^{k}\right)$ & 3.35 & 3.52 & 3.27 & 3.35 & 3.31 & 3.15 & 3.09 & 3.08 \\
\hline foreign bonds & $\operatorname{Var}\left(r_{t, b}^{k}-h_{t}^{k}\right)$ & 0.72 & 0.99 & 1.13 & 1.25 & 1.38 & 1.47 & 1.55 & 1.63 \\
\hline foreign bills & $\operatorname{Var}\left(r_{t, n}^{k}-h_{t}^{k}\right)$ & 0.88 & 1.17 & 1.31 & 1.46 & 1.59 & 1.69 & 1.76 & 1.83 \\
\hline
\end{tabular}

Notes to Table 3: Variables are defined as follows: $V_{t, c}^{k}=\frac{\operatorname{Var}\left(r_{t, c}^{k}\right)}{\operatorname{Var}\left(r_{t, c}^{k}-k_{t}^{k}\right)}$, where $r_{t, c}^{k}$ denotes the real return in the U.K. on U.S. CPI-linked real assets over a $k$-period horizon from a UK investor's perspective, and $h_{t}^{k}$ denotes the return on a pound hedge against the dollar; $V_{t, 0}^{k}=\frac{\operatorname{Var}\left(r_{t, 0}^{k}\right)}{\operatorname{Var}\left(r_{t, 0}^{k}-h_{i}^{k}\right)}$, where $r_{t, d}^{k}$ denotes the real return in the U.K. on U.S. stocks over a $k$-period horizon from a UK investor's perspective; $V_{t, b}^{k}=\frac{\operatorname{Var}\left(r_{t, b}^{k}\right)}{\operatorname{Var}\left(r_{t, b}^{k}-h_{t}^{k}\right)}$, where $r_{t, b}^{k}$ denotes the real return in the U.K. on U.S. bonds over a $k$-period horizon from a UK investor's perspective; and $V_{t, n}^{k}=\frac{\operatorname{Var}\left(r_{t, n}^{k}\right)}{\operatorname{Var}\left(r_{t, n}^{k}-k_{t}^{k}\right)}$, where $r_{t, n}^{k}$ denotes the real return in the U.K. on U.S. bills over a $k$-period horizon from a UK investor's perspective. 


\section{Table 4}

Real Return on Foreign Investments:

Estimated Minimum-Variance Hedge Ratios

Holding Horizon ( $k$ years)

\begin{tabular}{llllllllll} 
Variable & 1 & 2 & 3 & 4 & 5 & 6 & 7 & 8 \\
\hline
\end{tabular}

\begin{tabular}{|c|c|c|c|c|c|c|c|c|c|}
\hline \multirow[b]{2}{*}{ foreign real assets: } & \multirow[b]{2}{*}{$\beta_{c}^{k}$} & \multicolumn{8}{|c|}{ Minimum-Variance Ratios } \\
\hline & & 0.750 & 0.680 & 0.680 & 0.690 & 0.630 & 0.570 & 0.520 & 0.420 \\
\hline foreign stocks & $\beta_{s}^{k}$ & 0.920 & 0.620 & 0.390 & 0.370 & 0.330 & 0.340 & 0.370 & 0.370 \\
\hline foreign bonds & $\beta_{b}^{k}$ & 0.820 & 0.800 & 0.820 & 0.820 & 0.720 & 0.600 & 0.520 & 0.390 \\
\hline foreign bills & $\beta_{n}^{k}$ & 0.710 & 0.640 & 0.630 & 0.580 & 0.440 & 0.320 & 0.230 & 0.130 \\
\hline
\end{tabular}

Percentage Variance Reduction from Minimum-Variance Hedge

$\begin{array}{llllllllll}\text { foreign real assets } & \left(R^{2}\right)_{c}^{k} & 0.420 & 0.340 & 0.320 & 0.300 & 0.250 & 0.190 & 0.140 & 0.070 \\ \text { foreign stocks } & \left(R^{2}\right)_{s}^{k} & 0.120 & 0.060 & 0.030 & 0.020 & 0.020 & 0.010 & 0.010 & 0.010 \\ \text { foreign bonds } & \left(R^{2}\right)_{b}^{k} & 0.350 & 0.280 & 0.240 & 0.210 & 0.140 & 0.090 & 0.050 & 0.020 \\ \text { foreign bills } & \left(R^{2}\right)_{n}^{k} & 0.250 & 0.180 & 0.140 & 0.110 & 0.050 & 0.020 & 0.010 & 0.000\end{array}$

Standard Errors of Estimated Minimum-Variance Ratios

\begin{tabular}{|c|c|c|c|c|c|c|c|c|c|}
\hline foreign real assets & $\left(\sigma_{\beta}\right)_{c}^{k}$ & 0.080 & 0.090 & 0.100 & 0.100 & 0.110 & 0.120 & 0.140 & 0.170 \\
\hline foreign stocks & $\left(\sigma_{\beta}\right)^{k}$ & 0.190 & 0.180 & 0.210 & 0.240 & 0.260 & 0.290 & 0.370 & 0.510 \\
\hline foreign bonds & $\left(\sigma_{\beta}\right)_{b}^{k}$ & 0.110 & 0.140 & 0.170 & 0.180 & 0.200 & 0.230 & 0.280 & 0.370 \\
\hline foreign bills & $\left(\sigma_{\beta}\right)_{n}^{k}$ & 0.120 & 0.160 & 0.180 & 0.190 & 0.210 & 0.230 & 0.270 & 0.360 \\
\hline
\end{tabular}

Notes to Table 4: Minimum-variance ratios are estimates of $\beta_{l}^{k}$ from the regression $r_{t, 1}^{k}=$ $\alpha_{i}^{k}+\beta_{l}^{k} h_{t}^{k}+\epsilon_{t, 1}^{k}$, where $r_{t, 1}^{k}$ is the domestic $k$-period real return from holding foreign asset $l$, and $h_{t}^{k}$ is the $k$-period return on the currency hedge (the domestic currency return of borrowing in domestic currency to hold foreign deposits). Standard errors of estimated $\beta$ s are computed using the largest of several measures, including OLS, Newey-West serial-correlation consistent and Newey-West serial-correlation and heteroskedasticity consistent standard errors. 


\section{Table 5}

\section{Decomposition of Hedge Returns}

into:

\section{Real Interest Differentials and Changes in Real Exchange Rates}

$$
\begin{gathered}
h_{t}^{k} \equiv \Delta^{k} S_{t}+R_{t}^{k} \\
\equiv\left(x_{d, t}^{k}-\pi_{f, t}^{k}-\Delta^{k} s_{t}\right)+\sum_{j=0}^{k-1}\left(\left(i_{d, t+j}-x_{d, t+j}^{1}\right)-\left(i_{f, t+j}-\pi_{f, t+j}^{1}\right)\right) \\
\text { Variances: } \quad \text { Cross-correlations: }
\end{gathered}
$$

\begin{tabular}{|c|c|c|c|c|c|}
\hline & (1) & (2) & (3) & & \\
\hline Horizon & $h_{t}^{k}$ & $\Delta^{k} S_{t}$ & $R_{t}^{k}$ & $\rho_{1,2}$ & $\rho_{1,3}$ \\
\hline 1 & 0.006 & 0.008 & 0.005 & 0.647 & 0.272 \\
\hline 2 & 0.012 & 0.016 & 0.012 & 0.585 & 0.315 \\
\hline 3 & 0.016 & 0.023 & 0.017 & 0.562 & 0.301 \\
\hline 4 & 0.019 & 0.030 & 0.023 & 0.549 & 0.283 \\
\hline 5 & 0.022 & 0.035 & 0.029 & 0.496 & 0.313 \\
\hline 6 & 0.022 & 0.038 & 0.035 & 0.430 & 0.342 \\
\hline 7 & 0.021 & 0.040 & 0.039 & 0.368 & 0.349 \\
\hline 8 & 0.017 & 0.040 & 0.043 & 0.271 & 0.367 \\
\hline 9 & 0.018 & 0.042 & 0.046 & 0.232 & 0.390 \\
\hline 10 & 0.019 & 0.043 & 0.050 & 0.206 & 0.414 \\
\hline
\end{tabular}

Notes to Table 5: The term $h_{t}^{k}=\sum_{j=0}^{k-1}\left(\Delta^{k} s_{t}+i_{f, t+j}-i_{d, t+j}\right)$ is the $k$-period hedge return; $R_{t}^{k} \equiv \sum_{j=0}^{k-1}\left(\left(i_{f, t+j}-\pi_{f, t+j}^{1}\right)-\left(i_{d, t+j}-\pi_{d, t+j}^{1}\right)\right)$ is the $k$-period real interest differential, and $\Delta^{k} S_{t} \equiv \Delta^{k} s_{t}+\pi_{l, t}^{k}-\pi_{d, t}^{k}$ is the $k$-period change in the log of the real exchange rate. 


\section{Table 6}

Real Return on Foreign Investments:

Estimated Exposures to

Real Interest Differentials and Real Exchange Rate Changes

Holding Horizon ( $k$ years)

Asset

Variable

12

3

4

5

6

7

8

\begin{tabular}{lcccccccccc}
\multicolumn{10}{c}{ Exposure to Real Interest Differentials } \\
foreign stocks & $\beta_{1, \text { A }}^{k}$ & 0.226 & 0.014 & -0.234 & -0.414 & -0.449 & -0.398 & -0.350 & -0.257 \\
foreign bonds & $\beta_{1, b}^{k}$ & 0.099 & 0.105 & 0.087 & 0.011 & -0.097 & -0.160 & -0.218 & -0.259 \\
foreign bills & $\beta_{1, n}^{k}$ & 0.164 & 0.200 & 0.210 & 0.170 & 0.108 & 0.055 & 0.005 & -0.038 \\
& \multicolumn{8}{c}{ Exposure to Real Exchange Rate Changes } \\
foreign stocks & $\beta_{2, \downarrow}^{k}$ & 1.150 & 0.894 & 0.683 & 0.720 & 0.787 & 0.895 & 1.040 & 1.240 \\
foreign bonds & $\beta_{2, b}^{k}$ & 0.919 & 0.887 & 0.876 & 0.841 & 0.743 & 0.690 & 0.660 & 0.665 \\
foreign bills & $\beta_{2, n}^{k}$ & 1.040 & 1.080 & 1.110 & 1.110 & 1.070 & 1.020 & 1.000 & 0.997
\end{tabular}

Percentage of Variance Explained by Exposures

$\begin{array}{llllllllll}\text { foreign stocks } & \left(R^{2}\right)_{a}^{k} & 0.223 & 0.171 & 0.165 & 0.234 & 0.274 & 0.304 & 0.337 & 0.364 \\ \text { foreign bonds } & \left(R^{2}\right)_{b}^{k} & 0.508 & 0.413 & 0.364 & 0.344 & 0.297 & 0.262 & 0.246 & 0.243 \\ \text { foreign bills } & \left(R^{2}\right)_{n}^{k} & 0.661 & 0.580 & 0.532 & 0.509 & 0.459 & 0.406 & 0.372 & 0.347\end{array}$

Standard:Errors of Estimated Exposure to Real Interest Differentials

$\begin{array}{llllllllll}\text { foreign stocks } & \left(\sigma_{\beta}\right)_{k}^{k} & 0.229 & 0.237 & 0.258 & 0.285 & 0.283 & 0.293 & 0.349 & 0.419 \\ \text { foreign bonds } & \left(\sigma_{\beta}\right)_{b}^{k} & 0.136 & 0.169 & 0.188 & 0.200 & 0.209 & 0.224 & 0.257 & 0.320 \\ \text { foreign bills } & \left(\sigma_{\beta}\right)_{n}^{k} & 0.121 & 0.143 & 0.164 & 0.176 & 0.186 & 0.201 & 0.234 & 0.301\end{array}$

Standard Errors of Estimated Exposure to Real Exchange Rate Changes

$\begin{array}{llllllllll}\text { foreign stocks } & \left(\sigma_{\beta}\right)_{.}^{k} & 0.147 & 0.178 & 0.219 & 0.235 & 0.224 & 0.235 & 0.288 & 0.363 \\ \text { foreign bonds } & \left(\sigma_{\beta}\right)_{b}^{k} & 0.082 & 0.131 & 0.156 & 0.151 & 0.172 & 0.202 & 0.246 & 0.322 \\ \text { foreign bills } & \left(\sigma_{\beta}\right)_{n}^{k} & 0.060 & 0.083 & 0.102 & 0.109 & 0.128 & 0.153 & 0.195 & 0.276\end{array}$

Notes to Table 6: Exposure ratios, $\beta_{1,1}^{k}$ and $\beta_{2, l}^{k}$ are OLS estimates from the regression $r_{t, 1}^{k}=\alpha_{i}^{k}+\beta_{1,1}^{k} R_{t}^{k}+\beta_{2,1}^{k} \Delta^{k} S_{t}+\epsilon_{t, 1}^{k}$, where $r_{t, 1}^{k}$ is the domestic $k$-period real return from holding foreign asset $l, l=s, b, n ; R_{l}^{k} \equiv \sum_{j=0}^{k-1}\left(\left(i_{f, t+j}-x_{f, t+j}^{1}\right)-\left(i_{d, t+j}-x_{d, t+j}^{1}\right)\right)$ is the $k$-period real interest differential; and $\Delta^{k} S_{t} \equiv \Delta^{k} s_{t}+\pi_{j, t}^{k}-\pi_{d, t}^{k}$ is the $k$-period change in the log of the real 
exchange rate. Standard errors of estimated $\beta_{8}$ are computed using the largest of several measures, including OLS, Newey-West serial-correlation consistent and Newey-West serial-correlation and heteroskedasticity consistent standard errors. The panel entitled "percentage variance explained by exposures" represents the $R^{2}$ from the above regression. 
Table 7

\author{
Real Return on Foreign Investments: \\ Estimated Minimum-Variance Real Hedge Ratios
}

Holding Horizon ( $k$ years)

\begin{tabular}{|c|c|c|c|c|c|c|c|c|c|}
\hline & Variable & 1 & 2 & 3 & 4 & 5 & 6 & 7 & 8 \\
\hline & & \multicolumn{8}{|c|}{ Minimum-Variance Ratios } \\
\hline stocks & $\beta^{k}$ & 1.050 & 0.887 & 0.808 & 0.953 & 1.060 & 1.160 & 1.300 & 1.450 \\
\hline foreign bonds & $\beta_{b}^{k}$ & 0.968 & 0.981 & 0.995 & 1.010 & 1.000 & 0.987 & 0.998 & 1.030 \\
\hline foreign bills & $\beta_{n}^{k}$ & 0.875 & 0.834 & 0.829 & 0.835 & 0.803 & 0.798 & 0.821 & 0.878 \\
\hline
\end{tabular}

Percentage Variance Reduction from Minimum-Variance Hedge

$\begin{array}{llllllllll}\text { foreign stocks } & \left(R^{2}\right)_{c}^{k} & 0.219 & 0.171 & 0.159 & 0.216 & 0.253 & 0.289 & 0.327 & 0.359 \\ \text { foreign bonds } & \left(R^{2}\right)_{b}^{k} & 0.653 & 0.568 & 0.521 & 0.503 & 0.456 & 0.405 & 0.372 & 0.347 \\ \text { foreign bills } & \left(R^{2}\right)_{n}^{k} & 0.505 & 0.410 & 0.362 & 0.344 & 0.295 & 0.257 & 0.239 & 0.235\end{array}$

Standard Errors of Estimated Minimum-Variance Ratios

$\begin{array}{llllllllll}\text { foreign stocks } & \left(\sigma_{\beta}\right)_{c}^{k} & 0.145 & 0.160 & 0.170 & 0.170 & 0.169 & 0.178 & 0.187 & 0.199 \\ \text { foreign bonds } & \left(\sigma_{\beta}\right)_{b}^{k} & 0.080 & 0.106 & 0.121 & 0.123 & 0.129 & 0.138 & 0.150 & 0.170 \\ \text { foreign bills } & \left(\sigma_{\beta}\right)_{n}^{k} & 0.090 & 0.124 & 0.140 & 0.142 & 0.157 & 0.178 & 0.199 & 0.220\end{array}$

Notes to Table 7: Minimum-variance ratios are estimates of $\beta_{l}^{k}$ from the regression $r_{t, 1}^{k}=$ $\alpha_{l}^{k}+\beta_{l}^{k} \Delta^{k} S_{t}+\epsilon_{t, l}^{k}$, where $r_{t, l}^{k}$ is the domestic $k$-period real return from holding foreign asset $l$, and $\Delta^{k} S_{t}=\Delta^{k} s_{t}+\pi_{f, t}^{k}-\pi_{d, t}^{k}$ is the $k$-period change in the log of the real exchange rate (which can be interpreted as the return on a real currency hedge under the assumption that ex ante real interest rates are constant). Standard errors of estimated $\beta \mathrm{s}$ are computed using the largest of several measures, including OLS, Newey-West serial-correlation consistent and Newey-West serialcorrelation and heteroskedasticity consistent standard errors. 